\title{
Parâmetros físico químicos e microbiológicos de um sistema de compostagem de dejetos sólidos de suínos associado com resíduos de hortaliças
}

\begin{abstract}
Tanto a suinocultura como a horticultura são atividades do agronegócio com alto potencial gerador de resíduos sólidos. Tal situação tem levado a um passivo ambiental crescente nas duas atividades. Resíduos que dificultam o processo natural de degradação, como as hortaliças, tornam necessárias associações para facilitar seu tratamento. Dessa forma, o presente trabalho teve por objetivo geral avaliar os parâmetros físico químicos e microbiológicos de um sistema de compostagem de dejetos sólidos de suínos associado com resíduos de hortaliças. A pesquisa foi realizada na área experimental do Instituto Federal de Educação, Ciência e Tecnologia de São Paulo - Campus São Roque, durante o período de 77 dias. Foi feito um tratamento com três repetições na forma de canteiros, onde foram investigadas bactérias do grupo coliforme com um total de 11 coletas em cada canteiro, com intervalo semanal, sendo a primeira coleta realizada no primeiro dia da implantação. Em relação aos parâmetros físico químicos, foram analisados temperatura, pH e relação carbono nitrogênio. Os resultados revelaram que o sistema de compostagem apesar de não apresentar fase termofílica, com aumento de temperatura, apresentou a redução de bactérias do grupo coliforme termotolerante, importante grupo de micro-organismos indicadores de qualidade ambiental. Entretanto, em relação as bactérias do grupo coliformes totais mantiveram-se os valores em $240 \mathrm{UFC} / \mathrm{ml}$. $\mathrm{O}$ pH variou de levemente alcalino para ácido onde, por fim, voltou a se elevar na última semana. Quanto a relação carbono nitrogênio (RCN), o substrato inicial mostrou-se com valores acima do ideal para este tratamento. Porém, ao longo do processo foi observada grande redução nessa relação, mas que ainda não enquadra o composto nos resultados ideais para o tratamento utilizado.
\end{abstract}

Palavras-chave: Suinocultura; Horticultura; Bactérias; Temperatura; Biofertilizante.

\section{Physical chemical and microbiological parameters of a system of composting of solid waste of swine associated with vegetable residues}

\begin{abstract}
Both swine and horticulture are agribusiness activities with high potential for generating solid waste. This situation has led to a growing environmental liability in both activities. Residues that hinder the natural process of degradation, such as vegetables, make associations necessary to facilitate its treatment. In this context, the objective of the present work was to evaluate the physical chemical and microbiological parameters of a composting system of wastes solid of swine associated with residues of vegetables. The research was carried out in the experimental area of the Federal Institute of Education, Science and Technology of São Paulo - Campus São Roque, during the period of 77 days. Was made a treatment with three replicates was carried out in the form of beds, where bacteria of the coliform group were investigated, with a total of 11 collections in each bed, with weekly interval, being the first collection performed on the out in the form of beds, where bacteria of the coliform group were investigated, with a total of 11 collections in each bed, with weekly interval, being the first collection performed on the
first day of implantation. Regarding the chemical physical parameters, temperature, $\mathrm{pH}$ and carbon nitrogen ratio were analyzed. The results showed that the composting system, although
not presenting thermophilic phase, with temperature increase, showed the reduction of bacteria of the thermotolerant coliform group, an important group of microorganisms indicators not presenting thermophilic phase, with temperature increase, showed the reduction of bacteria of the thermotolerant coliform group, an important group of microorganisms indicators
environmental quality. However, the bacteria in the total coliforms group maintained their values at $240 \mathrm{CFU} / \mathrm{ml}$. The $\mathrm{pH}$ ranged from slightly alkaline to acid where it rose again in the las week. As to carbon nitrogen ratio (NR), the initial substrate showed values above the ideal for this treatment. However, throughout the process a great reduction in this relation was observed but it still does not frames the compound in the ideal results for the treatment used.
\end{abstract}

Keywords: Pig farming; Horticulture; Bacteria; Temperature; Biofertilizer.

Topic: Área Temática

Reviewed anonymously in the process of blind peer

Mayara Pereira Mendes Costa

Universidade de São Paulo, Brasil

http://lattes.cnpq.br/2204060955249105

mayara.costa@usp.br

Francisco Rafael Martins Soto

Instituto Federal de São Paulo, Brasi

http://lattes.cnpq.br/8697221494886208

http://orcid.org/0000-0002-7483-242X

sotofrm@ifsp.edu.br

Ricardo Augusto Rodrigues

Instituto Federal de São Paulo, Brasi

http://lattes.cnpq.br/6697645400414051

ricardo.augusto@ifsp.edu.com.br
Received: 12/02/2019

Approved: 28/03/2019
Giovanni Fatobene

Instituto Federal de São Paulo, Brasil

http://lattes.cnpq.br/3326320558903711

giovanni.fatobene10@gmail.com
Referencing this:

COSTA, M. P. M.; SOTO, F. R. M.; RODRIGUES, R. A.; FATOBENE, G. Parâmetros físico químicos e microbiológicos de um sistema de compostagem de dejetos sólidos de suínos associado com resíduos de hortaliças. Revista Ibero Americana de Ciências Ambientais, v.10, n.2, p.45-52, 2019. DOI: http://doi.org/10.6008/CBPC2179-

6858.2019.002.0005 


\section{INTRODUÇÃO}

O agronegócio é uma das principais competências nacionais, sendo parte fundamental no crescimento econômico do país (LIMA et al., 2017). A suinocultura e a horticultura, apesar de atividades distintas deste setor da economia, possuem elevada importância social e econômica. O mercado da suinocultura no Brasil está entre as atividades mais consolidadas do agronegócio, colocando o país o em 4ำ lugar nos rankings de maior produtor e exportador mundial de carne suína. No ano de 2017, de acordo com o relatório anual publicado pela ABPA (Associação Brasileira de Proteína Animal), o país produziu 3,75 milhões de toneladas, sendo que 697 mil foram exportadas. Tornando o Brasil responsável por cerca de 8,5\% da exportação mundial de carne suína (ABPA, 2018).

A horticultura, por outro lado, possui como um de seus principais colaboradores no processo de racionalizar a produção e comercialização a CEAGESP (Companhia de Entrepostos e Armazéns Gerais de São Paulo). Nesta organização passam, diariamente, toneladas de produtos altamente perecíveis. Entre esses, estão as hortaliças folhosas, que tem como principal responsável pelo abastecimento dos mercados da região metropolitana de São Paulo, o munícipio de Ibiúna/SP (COUTO, 2007). Na cidade, a produção é realizada por pequenas propriedades familiares, entre elas algumas certificadas de alimentos orgânicos, que variam de 2 a 10 ha (VALARINI et al., 2011).

Apesar das características que diferem as atividades, ambas apresentam alto potencial gerador de resíduos sólidos, que quando não tratados ou manejados corretamente causam prejuízos ambientais. A produção de alimentos altamente perecíveis, como as hortaliças folhosas, tem sua durabilidade intimamente relacionada a todas as etapas de produção e comercialização. Nestes produtos, qualquer alteração nas características intrínsecas ou extrínsecas fazem com que este perca seu valor comercial, provocando sua rejeição tanto pelo varejista, quanto pelo consumidor. Além disso, a coleta e o tratamento de resíduos, que se fazem necessários com a sua perda, têm alto custo financeiro, social e ambiental (FAGUNDES et al., 2012).

A suinocultura, dentre as atividades agropecuárias, é considerada pelos órgãos de controle ambiental a atividade com maior potencial poluidor. A expansão da atividade no Brasil, tem como principal característica a concentração de animais confinados em pequenas áreas, visando atender o consumo nacional e internacional. Como consequência dessa concentração, pode-se verificar o aumento dos dejetos e, assim, da preocupação com seus impactos sobre o meio ambiente. Uma vez que os dejetos suínos, quando dispostos de maneira inadequada, podem causar a poluição de lençóis freáticos, desequilíbrio dos nutrientes do solo, contaminação de culturas por meio da transmissão de patógenos, além de produzirem gases nocivos ao ambiente (RIZZONI et al., 2012).

A situação das atividades, somada ao potencial de expansão no país, tem levado a um aumento no impacto ambiental causado pela disposição inadequada desses resíduos (TONIAZZO et al., 2018). Entre as possíveis alternativas de tratamento, a de maior aceitação pelos agricultores é a utilização dos dejetos como fertilizante (CARDOSO et al., 2015). A compostagem é apontada como uma importante alternativa sustentável para o tratamento de resíduos orgânicos nas suas etapas iniciais, agregando valor comercial a 
um produto antes considerado desperdício (GASPODINI et al., 2018). A técnica consiste em um processo simples e de baixo custo, onde uma população diversificada de micro-organismos, em condições adequadas de temperatura, umidade e aerobiose promovem a degradação de resíduos orgânicos, e fornece como produto um composto estável e rico em matéria orgânica, usado como fertilizante na agricultura (OLIVEIRA et al., 2017).

Este composto quando empregado no solo proporciona benefícios agronômicos, como elevação do $\mathrm{pH}$ e aumento na disponibilidade de macronutrientes, além de representar um benefício de ordem social, devido à disposição final menos impactante no ambiente (RODRIGUES et al., 2011). Ademais devido ao seu valor agronômico é uma importante fonte de renda alternativa para o suinocultor e o horticultor.

Dejetos sólidos de suínos são considerados uma fonte rica de nutrientes para o crescimento de micro-organismos decompositores, em sua composição podemos encontrar os principais macronutrientes em quantidades satisfatórias como carbono, nitrogênio e fósforo (SANCHES et al., 2016). Já os resíduos de hortaliças, são fontes pobres desses macronutrientes necessários, além disso possuem alto teor de umidade, o que pode dificultar o processo de decomposição (RODRIGUES et al., 2017).

Neste contexto, tornam-se necessárias investigações com o objetivo de associar diferentes tipos de matérias orgânicas que permitem avanços no tratamento destes resíduos, muitas vezes difíceis de serem tratados a partir da técnica de compostagem quando não associados. O presente trabalho vem de encontro a essa necessidade com o objetivo de avaliar parâmetros físico-químicos $(\mathrm{pH}$, temperatura e relação carbono nitrogênio) e microbiológicos (bactérias do grupo coliforme) de um sistema de compostagem de dejetos sólidos de suínos associado com resíduos de hortaliças.

\section{MATERIAIS E MÉTODOS}

O trabalho foi realizado na área experimental do IFSP - Campus São Roque, com período de duração de 77 dias, tendo início no dia 26 de setembro de 2017. Foi feito um tratamento com três repetições na forma de canteiros. Cada canteiro se encontrava em local protegido contra a incidência de chuva e de raios solares diretos, sendo constituído em alvenaria (bloco de cimento) com altura de 0,8 metros, meio de largura e um de comprimento. Totalizando 0,4 metros cúbicos de volume. 0 piso impermeabilizado com concreto impedia a contaminação do lençol freático devido a produção de chorume. Este líquido resultante da decomposição da matéria orgânica foi retido em um tanque com fundo também impermeabilizado.

Os resíduos de hortaliças e os dejetos sólidos de suínos foram colocados nos canteiros na forma de 'sanduíche', na proporção de 3:1, hortaliças e dejetos de suínos, respectivamente. Para a pesquisa das bactérias do grupo coliforme, parâmetro utilizado para análise microbiológica, foram efetuadas 11 coletas em cada canteiro com intervalo semanal, sendo a primeira realizada no primeiro dia da implantação. As amostras foram coletadas de quatro pontos da área de cada canteiro em específico, para permitir uma maior fidelidade no resultado amostral.

A partir das amostras coletadas, com aproximadamente 100 gramas e em condições de assepsia, as análises bacteriológicas e a determinação de unidades formadoras de colônias (UFC) foram efetuadas com o 
uso da técnica utilizada por Vanderzant et al. (1992) e Silva et al. (2007). Os parâmetros físico químicos analisados no sistema de compostagem foram: temperatura, pH e relação carbono nitrogênio (RCN).

A temperatura foi aferida diariamente às 15 horas, desde o dia zero, com a introdução do termômetro de mercúrio durante três minutos no interior dos canteiros. Para a investigação do pH e da RCN foram efetuadas coletas de amostras para cada parâmetro, com intervalo semanal, sendo a primeira coleta também realizada no primeiro dia da implantação. Em relação à determinação do $\mathrm{pH}$ foi utilizado o método de diluição de 10 gramas de amostra em $100 \mathrm{ml}$ de água destilada para que, utilizando fita universal e a escala de cores ( $\mathrm{pH}^{0}-14$, Merck $^{\circledR}$ ), fosse determinado o valor do $\mathrm{pH}$ do sistema de compostagem. Para a RCN foi utilizada a técnica analítica de titulometria, e posterior cálculo (SZAKACS, 2003).

\section{RESULTADOS}

O Gráfico 1 aponta os resultados da variação de temperatura média semanal nos quatro canteiros do sistema de compostagem de resíduos sólidos de suínos associados aos resíduos de hortaliças.

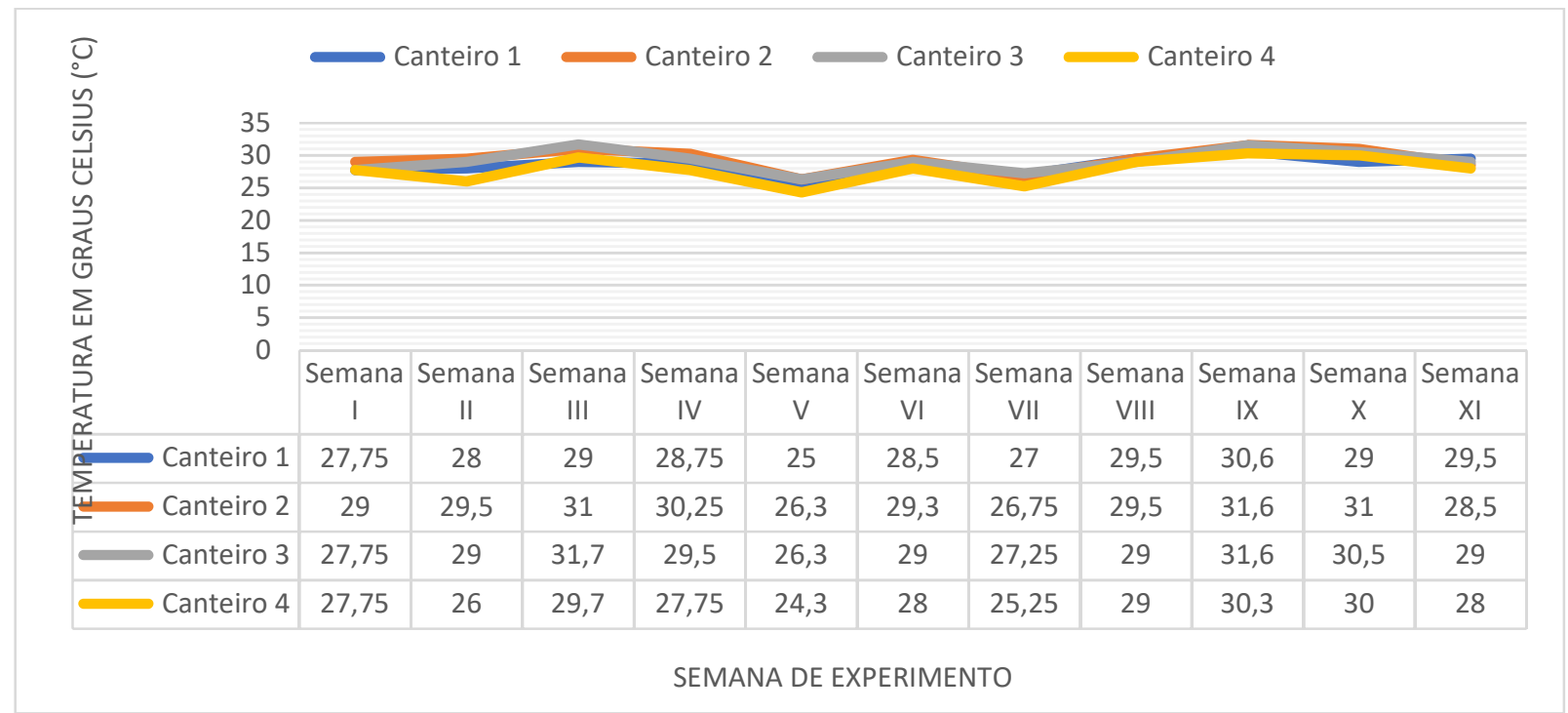

Gráfico 1: Variações médias semanais de temperatura, em graus Celsius (ํㅡ), no sistema de compostagem com dejetos sólidos de suínos e resíduos de hortaliças nas 11 semanas investigadas e nos respectivos canteiros.

$\mathrm{Na}$ Tabela 1 estão apresentados os resultados de coliformes totais no sistema de compostagem de dejetos sólidos de suínos associados aos resíduos de hortaliças. Na Tabela 2 estão apresentados os resultados obtidos a partir da investigação de coliformes termotolerantes do sistema de compostagem de dejetos sólidos de suínos associados aos resíduos de hortaliças. Na Tabela 3 encontram-se os resultados da variação de $\mathrm{pH}$ durante as onze semanas investigadas no sistema de compostagem com dejetos sólidos de suínos e resíduos de hortaliças. A Tabela 4 apresenta a variação entre os resultados alcançados da relação carbono e nitrogênio durante as onze semanas investigadas no sistema de compostagem de dejetos sólidos de suínos e resíduos de hortaliças. 
Tabela 1: Resultados das análises de coliformes totais em UFC/ml no sistema de compostagem com dejetos sólidos de suínos e resíduos de hortaliças nas 11 semanas investigadas e nos respectivos canteiros.

\begin{tabular}{|c|c|c|c|c|}
\hline \multicolumn{5}{|c|}{ Coliformes totais (UFC/ml) } \\
\hline Semana & Canteiro 1 & Canteiro 2 & Canteiro 3 & Canteiro 4 \\
\hline 1 & 240 & 240 & 240 & 240 \\
\hline II & 240 & 240 & 240 & 240 \\
\hline III & 240 & 240 & 240 & 240 \\
\hline IV & 240 & 240 & 240 & 240 \\
\hline $\mathrm{V}$ & 240 & 240 & 240 & 240 \\
\hline VI & 240 & 240 & 240 & 240 \\
\hline VII & 240 & 240 & 240 & 240 \\
\hline VIII & 240 & 240 & 240 & 240 \\
\hline IX & 240 & 240 & 240 & 240 \\
\hline$x$ & 240 & 46 & 21 & 240 \\
\hline $\mathrm{XI}$ & 240 & 240 & 240 & 240 \\
\hline
\end{tabular}

Tabela 2: Resultados das análises de coliformes termotolerantes em UFC/ml no sistema de compostagem com dejetos sólidos de suínos e resíduos de hortaliças nas 11 semanas investigadas e nos respectivos canteiros.

\begin{tabular}{|l|l|l|l|l|}
\hline \multicolumn{2}{|l|}{ Coliformes termotolerantes (UFC/mI) } \\
\hline Semana & Canteiro 1 & Canteiro 2 & Canteiro 3 & Canteiro 4 \\
\hline I & 0,62 & 1,1 & 9,3 & 0,91 \\
\hline II & 0,3 & 0,3 & 0,3 & 0,3 \\
\hline III & 0,3 & 0,3 & 0,3 & 0,3 \\
\hline IV & 0,3 & 0,3 & 0,3 & 0,3 \\
\hline V & 0,3 & 0,3 & 0,3 & 0,3 \\
\hline VI & 0,3 & 0,3 & 0,3 & 0,3 \\
\hline VII & 0,3 & 0,3 & 0,3 & 0,3 \\
\hline VIII & 0,3 & 0,3 & 0,3 & 0,3 \\
\hline IX & 0,3 & 0,3 & 0,3 & 0,3 \\
\hline$X$ & 0,3 & 0,3 & 0,3 & 0,3 \\
\hline$X I$ & 0,3 & 0,3 & 0,3 & 0,3 \\
\hline
\end{tabular}

Tabela 3: Resultados das análises de pH no sistema de compostagem com dejetos sólidos de suínos e resíduos de hortaliças nas 11 semanas investigadas e nos respectivos canteiros.

\begin{tabular}{|l|l|l|l|l|}
\hline $\mathrm{pH}$ & Canteiro 1 & Canteiro 2 & Canteiro 3 & Canteiro 4 \\
\hline Semana & 8 & 8 & 8 & 8 \\
\hline $\mathrm{I}$ & 8 & 8 & 8 & 8 \\
\hline $\mathrm{II}$ & 7 & 8 & 8 & 7 \\
\hline $\mathrm{III}$ & 5 & 6 & 5 & 5 \\
\hline $\mathrm{IV}$ & 5 & 5 & 5 & 5 \\
\hline $\mathrm{V}$ & 6 & 5 & 5 & 5 \\
\hline $\mathrm{VI}$ & 5 & 5 & 5 & 5 \\
\hline $\mathrm{VII}$ & 5 & 5 & 5 & 5 \\
\hline $\mathrm{VIII}$ & 5 & 5 & 5 & 5 \\
\hline $\mathrm{IX}$ & 5 & 4 & 5 & 5 \\
\hline $\mathrm{X}$ & 6 & 5 & 6 & 6 \\
\hline $\mathrm{XI}$ & & & & \\
\hline
\end{tabular}

Tabela 4: Resultados da relação carbono nitrogênio (RCN) no sistema de compostagem com dejetos sólidos de suínos e resíduos de hortaliças nas 10 semanas investigadas e nos respectivos canteiros.

\begin{tabular}{|l|l|l|l|l|}
\hline RCN & Canteiro 1 & Canteiro 2 & Canteiro 3 & Canteiro 4 \\
\hline Semana & 64,4 & 73,3 & 70,7 & 68,0 \\
\hline I & 46,5 & 52,8 & 61,6 & 65,1 \\
\hline II & 40,6 & 51,3 & 55,6 & 63,9 \\
\hline III & 36,1 & 51,0 & 51,8 & 63,4 \\
\hline IV & 34,2 & 49,0 & 51,0 & 59,8 \\
\hline V & 31,1 & 45,3 & 48,5 & 50,8 \\
\hline VI & 28,3 & 42,2 & 46,6 & 44,3 \\
\hline VII & 27,3 & 42,1 & 45,1 & 37,1 \\
\hline VIII & 23,8 & 39,8 & 42,5 & 35,3 \\
\hline IX & 22,3 & 39,0 & 36,4 & 33,9 \\
\hline X & 21,3 & 37,0 & 36,4 & 33,7 \\
\hline XI & & & \\
\hline
\end{tabular}




\section{DISCUSSÃO}

Os resultados referentes à temperatura (Gráfico 1) indicaram que o sistema de compostagem não apresentou a fase termofílica, onde ocorre aumento da temperatura em função da atividade microbiana no interior do sistema, mantendo os valores entre $25^{\circ} \mathrm{C}$ e $32^{\circ} \mathrm{C}$. Próximo a temperatura ambiente. Fato que pode ser explicado pelo alto teor de umidade fornecido ao sistema a partir dos resíduos de hortaliças, que evitaram grandes variações de temperatura. Resultados distintos aos encontrados por Manarelli et al. (2015), em sistema de compostagem com resíduos sólidos de abatedouro avícola associado a palha de arroz, em que foram registradas temperaturas acima de $50 \circ \mathrm{C}$ e, em seguida, a estabilização em torno de $20^{\circ} \mathrm{C}$.

Os valores encontrados de bactérias do grupo coliforme total (Tabela 1) mantiveram-se em 240 UFC/ml, tendo redução inesperada apenas nos canteiros 2 e 3, em análise realizada na décima semana de experimento. Entretanto, esses resultados voltaram aos valores iniciais na semana seguinte, evidenciando que o sistema foi incapaz de reduzir bactérias deste grupo. Resultados semelhantes aos encontrados por Soto et al. (2017) em experimento de compostagem com hortaliças, utilizando a serragem e o capim seco como diferentes substratos. Neste, porém, as bactérias do grupo coliforme total se mantiveram em 240 UFC/ml ao longo de todo o experimento. Apesar de não apresentada a fase de termofilia, e da não redução de bactérias do grupo coliforme total, o sistema de compostagem investigado evidenciou a redução de bactérias do grupo coliforme termotolerante (Tabela 2).

Este importante grupo de micro-organismos, que em sua maioria são encontrados no intestino de mamíferos, podem causar distúrbios gastrointestinais. Sendo assim, são utilizados como indicadores de qualidade ambiental, acusando possível contaminação por outros microrganismos patógenos tais como vírus e bactérias, também presentes nas fezes de animais homeotérmicos (SOUZA et al., 2011). De acordo com as análises, pode-se verificar que, este grupo de micro-organismos teve redução observada a partir da segunda semana de experimento. Resultados controversos aos encontrados por Orrico Junior et al. (2009), que afirma a necessidade de temperaturas elevadas por vários dias para a redução de bactérias deste grupo. Em seu sistema de compostagem de dejetos de bovino Orrico Junior et al. (2012) também observou uma redução de bactérias do grupo coliforme termotolerante, ao ponto de não serem mais detectadas.

Outro parâmetro físico químico analisado, o pH, mostrou que houve alteração de seu valor no sistema, variando de levemente alcalino para ácido durante o intervalo que responde as onze semanas do experimento. Processo que ocorre naturalmente na compostagem devido à decomposição da matéria orgânica. Sendo assim, de acordo com Valente et al. (2009) os canteiros se mantiveram na faixa ótima para o desenvolvimento dos micro-organismos responsáveis pela decomposição. Faixa que situa-se entre 5 e 8. Uma vez que a maioria das enzimas se encontram ativas nesta faixa.

Os valores iniciais registrados, levemente alcalinos, podem estar relacionados a natureza do material a ser compostado. Ao decorrer do processo, os valores de $\mathrm{pH}$ reduzem para uma faixa com valores entre $5 \mathrm{e}$ 6. Resultados opostos aos obtidos por Pedrosa et al. (2013) em sistema de compostagem de resíduos agroindustriais, onde o pH manteve-se levemente alcalino do início ao fim do período investigado. 
Ao longo do processo de compostagem, o período em que ocorre a redução do pH é seguido novamente pelo seu aumento, devido a decomposição dos ácidos resultantes da ação de fungos e bactérias no consumo da matéria orgânica. Como foi observado por Heck et al. (2013) em sistema de compostagem de resíduos orgânicos domiciliares, onde os valores se estabilizaram em torno de 7,5. Fato que pode explicar a elevação do pH observado na semana XI.

Os altos valores iniciais obtidos da RCN a partir dos substratos utilizados evidenciam que estes encontram-se acima da faixa de variação considerada ideal, entre 25:1 e 30:1, por Silva et al. (2008) para o início do processo de compostagem. Entretanto, o mesmo autor afirma uma amplitude maior da faixa considerada aceitável, de 20:1 a 70:1, para o início do processo, no qual o substrato enquadra-se.

Ao longo do período investigado a relação tendeu a reduzir para valores em uma faixa de 21 a 37, ainda sendo superiores a relação de 10:1 considerada como ideal por Orrico Junior et al. (2009). Resultados controversos aos encontrados pelo autor em sistema de compostagem de água residuária da suinocultura associado aos dejetos de suínos, onde a RCN esteve abaixo do considerado ideal, com valor de 2,62. Essas diferenças, provavelmente, podem ser atribuídas principalmente às características físico químicas e biológicas dos substratos e, consequentemente, à facilidade de degradação destes.

\section{CONCLUSÕES}

Com base nos resultados obtidos é possível concluir que o sistema de compostagem de dejetos sólidos de suínos associado com resíduo de hortaliças foi incapaz de reduzir bactérias do grupo coliformes totais. Mas que, apesar de não apresentar grandes variações de temperatura em fase de termofilia, reduziu as bactérias do grupo coliformes termotolerantes, importantes micro-organismos indicadores de qualidade ambiental.

Durante o período investigado a variação de $\mathrm{pH}$ de levemente alcalino para ácido pode ser explicada pelo processo de decomposição da matéria orgânica. Porém, o composto, durante a última semana analisada, tendia a aumentar novamente estes valores, em processo apontado como natural na degradação. No que diz respeito à relação carbono nitrogênio o substrato mostrou-se inadequado com elevados valores iniciais, o que no decorrer das semanas tendiam a reduzir, porém ainda não enquadrando o composto final na relação 10:1 considerada ideal no processo de compostagem.

À vista disso, nota-se a possibilidade de associação de diferentes substratos em sistema de compostagem para acelerar a degradação de compostos que apresentam características que dificultam o processo, como é o caso das hortaliças. Sendo assim, sugere-se que em pesquisas futuras seja feito o controle da melhor proporção inicial de cada substrato utilizado, visando maior eficiência do sistema de compostagem e a qualidade do composto final.

\section{REFERÊNCIAS}

ABPA. Associação Brasileira de Proteína Animal. Relatório Anual 2018. 2018.
CARDOSO, B. F.; OYAMADA, G. C.; SILVA, C. M.. Produção, tratamento e uso dos dejetos suínos no Brasil.

Desenvolvimento em questão, v.13, n.32, p.127-145, 2015. 
COUTO, E.. As modernizações e as racionalidades na agricultura e o uso do território: temporalidades e espacialidades no município de Ibiúna (SP). Tese (Doutorado em Geografia Humana) - Universidade de São Paulo, São Paulo, 2007.

FAGUNDES, P. R. S.; SILVA, R. O. P.; NACHILUK, K.; MONDINI, L.. Aproveitamento dos resíduos gerados no entreposto terminal de São Paulo da CEAGESP. Informações Econômicas, v.42, n.3, 2012.

GASPODINI, R. S.; PRIETTO, P. D. M.; COLLA, L. M.; MARGARITES, A. C. F.. Compostagem de resíduos de casca de ovo, esterco bovino e lodo de estação de tratamento de efluente de graxaria: uma abordagem experimental em pequena escala. Revista CIATEC-UPF, v.10, n.1, p.1-16, 2018

HECK, K.; MARCO, E. G.; HAHN, A. B. B.; KLUGE, M.; SPILKI, F. R.; SAND, S. T. V. D.. Temperatura de degradação de resíduos em processo de compostagem e qualidade microbiológica do composto final. Revista Brasileira de Engenharia Agrícola e Ambiental, v.17, n.1, p.54-59, 2013.

LIMA, J. R.; POZO, O. V.; FREITAS, R. R.; MAURI, G. N.. Startups no agronegócio brasileiro: uma revisão sobre as potencialidades do setor. Brazilian Journal of Production Engineering (BJPE), v3, n.1, p.07-121, 2017.

MANARELLI, D. M.; ORRICO, A. C. A.; SUNADA, N. S.; OLIVEIRA, A. B. M.; CENTURION, S. R.; ORRICO JUNIOR, A. P.; MOURA, A. H. N.; FARIAS, R. M.. Compostagem de resíduo sólido de abatedouro avícola. Ciência Rural, v.45, n.1, p.178183, 2015.

OLIVEIRA, L. G. SOUZA, J. T. FRANCISCO, A. C.. Tratamento de dejetos suínos: oportunidades de conversão em energia. Revista Gestão Industrial, v.13, n.3, p.22-36, 2017.

ORRICO JUNIOR, M. A. P.; ORRICO, A. C. A.; LUCAS JUNIOR, J.. Compostagem da fração sólida da água residuária de suinocultura. Engenharia Agrícola, v.29, n.3, p.483-491, 2009.

ORRICO JUNIOR, M. A. P.; ORRICO, A. C. A.; LUCAS JUNIOR, J.; SAMPAIO, A. A. M.; FERNANDES, A. R. M.; OLIVEIRA, E. A. Compostagem dos dejetos da bovinocultura de corte: influência do período, do genótipo e da dieta. Revista Brasileira de Zootecnia, v.41, n.5, p.1301-1307, 2012.

PEDROSA, T. D.; FARIAS, C. A. S.; PEREIRA, R. A.; PEREIRA, R. A.; FARIAS, E. T. R.. Monitoramento dos parâmetros físicoquímicos na compostagem de resíduos agroindustriais. Nativa Sinop., v.1, n.1, p.44-48, 2013.

RIZZONI, L. B.; TOBIAS, A. C. T.; DEL BIANCHI, M.; GARCIA, J. A. D.. Biodigestão anaeróbica no tratamento de dejetos de suínos. Revista Científica Eletrônica de Medicina Veterinária, v.9, n.18, 2012.
RODRIGUES, J. C. W.; PEREIRA, C. E.; PAES, L. F.; SANTOS, J. C. N.; BORDINHON, A. M.. Utilização de Resíduos Agrícolas na Produção de Mudas de Rúcula (Eruca sativa) e Alface (Lactuca sativa). Cadernos de Agroecologia, v.11, n.2, 2017.

RODRIGUES, P. N.; ROLIM, P. M.; NETO, E. B.; COSTA, R. N. T. PEDROSA, E. M. R. OLIVEIRA, V. S.. Efeito do composto orgânico e compactação do solo no milho e nutrientes do solo. Revista Brasileira de Engenharia Agrícola e Ambiental. v.15, n.8, p.788-793, 2011.

SANCHES, R.; RODRIGUES, G. A.; FÁTIMA G. S.; PIQUERA, S.; PROENÇA, U. C. M.. Manejo dos dejetos em uma propriedade em Itápolis/SP. Ciência \& Tecnologia, v.8, p.159-163, 2016

SILVA, A. G.; LEITE, V. D.; SILVA, M. M. P.; PRASAD, S.; FEITOSA, W. B. S.. Compostagem aeróbia conjugada de lodo de tanque séptico e resíduos sólidos vegetais. Engenharia Sanitária Ambiental, v.13, n.4, p.371-379, 2008.

SILVA, N.; JUNQUEIRA, V. C. A.; SIVEIRA, N. F. A.. Manual de métodos de análises microbiológicas de alimentos. 3 ed. Livraria Varela, 2007.

SOTO, F. R. M.; MOURA, S. L.; NÓBREGA, L. P.; AZEVEDO, S. S.. Pesquisa de coliformes em compostagem de resíduos de hortaliças com a utilização de diferentes substratos. Revista Agrogeoambiental, Pouso Alegre, v.9, n.2, 2017.

SOUZA, J. A. A.; BATISTA, R. O.; RAMOS, M. M.; SOARES, A. A.. Contaminação microbiológica do solo com esgoto sanitário. Acta Scientiarum Technology, Maringá, v.33, n.1, p.5-8, 2011.

SZAKACS, G. G. J.. Sequestro de carbono nos solos: avaliação das potencialidades dos solos arenosos sob pastagens. Anhembi-Piracicaba/SP. Dissertação (Mestrado) Universidade de São Paulo, Piracicaba, 2003.

TONIAZZO, F.; RODRIGUES, A. C.; ROSA, M. M.; ROSA, C. O.; BECEGATO, V. A.; LAVNITCKI, L.; HENKES, J. A.; CANTONI, F.. Avaliação da liberação de $\mathrm{CO} 2$ em solo com adição de águas residuárias suínicolas e impactos ambientais e sociais da suinocultura. Revista Gestão \& Sustentabilidade Ambiental, Florianópolis, v.7, n.1, p. 253-274, 2018.

VALARINI, P. J.; OLIVEIRA, F. R. A.; SCHILICKMANN, S. F.; POPPI, R. J.. Qualidade do solo em sistemas de produção de hortaliças orgânico e convencional. Horticultura Brasileira, Brasília, v.29, n.4, 2011.

VALENTE, B. S.; XAVIER, E. G.; MORSELLI, T. B. G. A.; JAHNKE, D. S.; BRUM JUNIOR, B. S.; CABRERA, B. R.; MORAES, P. O.; LOPES, D. C. N.. Fatores que afetam o desenvolvimento da compostagem de resíduos orgânicos. Archivos de Zootecnia, v.58, p.59-85, 2009

VANDERZANT, C.; SPLITTSTOESSER, D. F.. Compendium of methods for microbiological examination for foods. 3 ed. Washington: American Public Health Association, 1992.

A CBPC - Companhia Brasileira de Produção Científica (CNPJ: 11.221.422/0001-03) detém os direitos materiais desta publicação. Os direitos referem-se à publicação do trabalho em qualquer parte do mundo, incluindo os direitos às renovaçôes, expansões e disseminações da contribuič̃o, bem como outros direitos subsidiários. Todos os trabalhos publicados eletronicamente poderão 作 preservam os direitos autorais, mas não têm permissão para a publicação da contribuição em outro meio, impresso ou digital, em português ou em tradução. 